\title{
Aspiration: diagnostic contributions from bedside swallowing evaluation and endoscopy
}

\author{
Aspirazione: contributo diagnostico dalla valutazione clinica non strumentale \\ ed endoscopica \\ D. FARNETI' ${ }^{1}$, V. TURRONI' , E. GENOVESE ${ }^{2}$ \\ ${ }^{1}$ Audiology Phoniatry Service, Infermi Hospital, AUSL Romagna, Rimini, Italy; ${ }^{2}$ Audiology Service, Policlinico Modena, Italy
}

\section{SUMMARY}

The aim of this study was to identify which characteristics, collected by bedside swallowing evaluation (BSE) and fiberoptic endoscopic evaluation of swallowing (FEES), are a risk or a protective factor for aspiration. This retrospective study included data on 1577 consecutive patients, collected by BSE and FEES. Bivariate analysis was performed to verify the association of each variable with aspiration (ChiSquare test). The variables associated with aspiration were entered into a multivariate logistic model to quantify this association. Several variables were significantly associated $(\mathrm{p}<0.05)$ with aspiration; cooperation, sensation, laryngeal elevation and direct therapy were found to be protective factors against aspiration. The regression model identified the most variables related with aspiration, among which tracheotomy, material pooling and spillage. Patients able to perform dry swallows were $77 \%$ less likely to aspirate (protective factor). Several variables are involved in protection of airways during swallowing. Their interaction, in patients with swallowing disorders, offers the clinician the best means of interpreting BSE and FEES.

KEY WORDS: Deglutition disorders • Aspiration • Residue • FEES • Bedside swallowing evaluation

\section{RIASSUNTO}

Lo scopo di questo studio è stato quello di identificare quali caratteristiche, raccolte dalla valutazione clinica non strumentale della deglutizione (BSE) e dalla valutazione fibroendoscopica della deglutizione (FEES), costituiscono un rischio o un fattore protettivo per l'aspirazione. Questo studio retrospettivo comprende dati da 1577 pazienti consecutivi, raccolti con la BSE e FEES. È stata eseguita un'analisi bivariata per verificare l'associazione di ciascuna variabile con l'aspirazione (Chi-Square test). Le variabili associate all'aspirazione sono state inserite in un modello logistico multivariato per verificare e quantificare questa associazione. Diverse variabili sono state trovate significativamente associate (valore di p inferiore a 0,05) con l'aspirazione, alcune rappresentando un fattore protettivo contro l'aspirazione: collaborazione, sensibilità, elevazione laringea, terapia diretta. La regressione logistica ha individuato le variabili più correlate all'aspirazione, tra cui la tracheotomia, il materiale che ristagna e che penetra. I pazienti in grado di eseguire deglutizioni a vuoto sono per il $77 \%$ meno esposti ad aspirazione (fattore protettivo). Diverse variabili sono coinvolte nella protezione delle vie aeree durante la deglutizione. La loro interazione, nei pazienti con disturbi di deglutizione, offre al clinico il modo migliore per interpretare i dati della BSE e FEES.

PAROLE CHIAVE: Disordini della deglutizione $\bullet$ Aspirazione $\bullet$ Ristagno $\bullet$ FEES $\bullet$ Valutazione clinica non strumentale

Cite this article as: Acta Otorhinolaryngol Ital 2018;38:511-516. https://doi.org/10.14639/0392-100X-1967

(C) Società Italiana di Otorinolaringoiatria e Chirurgia Cervico-Facciale

\section{Introduction}

Dysphagia defines any difficulty in the progression of the bolus or secretions through the cavities of the upper digestive tract while being kept out from the airway ${ }^{1}$. If airway protection is not guaranteed, material can reach the vocal cords by keeping it above (penetration) or below (aspiration), with or without reaction from the patient. Airway invasion is strictly related with pneumonia and chronic bronchial inflammation ${ }^{2}$.
Dysphagia is related to several pathological conditions and to aging ${ }^{3}$. In clinical practice, the possibility of identifying patients at risk of penetration or aspiration in a heterogeneous population is a priority, particularly in settings where the number of patients with impaired swallowing is high (nursing homes, healthcare facilities). In these contexts, patients suspected of having swallowing impairments are submitted to screening or bedside procedures (bedside swallowing evaluation, BSE) ${ }^{45}$, performed with the aim of identifying those who are at risk 
of dysphagia or aspiration, and should determine a further need for instrumental assessments. BSE does not only lack sensitivity and specificity in determining aspiration, but also in determining the underlying swallowing physiology. Thus, to fill this gap an instrumental assessment of swallowing is necessary. The instrumental assessment, be it fiberoptic ${ }^{6}$ or modified barium swallow exam (MBS) ${ }^{7}$, defines the altered physiology and severity, and aids the team in planning treatment strategies. A documented airway invasion does not define, per sè, the clinical severity of swallowing impairment, which may depend on other factors such as oral intake level and type of diet, quality of life related to dysphagia and self-perceived dysphagia symptoms ${ }^{89}$. Therefore, any instrumental result (able to express a criterion of severity) has to be contextualised into a wider clinical scenario, bearing in mind that the non-instrumental assessment tends to underestimate the risk of aspiration, whereas the instrumental assessment tends to overestimate it ${ }^{1011}$.

Previous studies ${ }^{11} 12$ have documented the possibility of identifying subjects who are at risk of aspiration by combining certain BSE and instrumental parameters, resulting in a clinical scale of dysphagia severity. Other scales, according to the estimated severity, give information about therapeutic options ${ }^{13}$.

With this premise, the aim of this study is to evaluate correlations among clinical information taken from BSE and FEES, and aspiration, in a large sample of patients with different clinical characteristics. The weight of this interaction was considered. Data from such a large sample can reinforce their generalisation and offer parameters to consider in conceiving new clinical scales.

\section{Materials and methods}

A retrospective analysis was performed on 1577 consecutive adult patients evaluated at our Swallowing Centre from mid-1998 to the end of 2006. Each patient provided his/her clinical history and underwent bedside and complete endoscopic evaluation with bolus tests. Data collection and bedside evaluation were performed alternately by three Speech Pathologists and a Phoniatrician.

Considering the retrospective nature of the study, the heterogeneity of the sample, the evaluators and long-term observation, the data available were considered globally. Table I reports the parameters and characteristics of participants included in the study. With respect to the clinical history, the following data were taken into account: age, sex, pathological conditions causing dysphagia, presence of tracheotomy, alternatives to oral feeding (via tubes or parenterally), previous dysphagia therapies (indirect thera-
Table I. Characteristics of study participants.

\begin{tabular}{|c|c|c|c|}
\hline Characteristics & & No. & $\%$ \\
\hline Age over 65 years & $\mathrm{H}$ & 878 & $55.68 \%$ \\
\hline Male & $\mathrm{H}$ & 622 & $39.44 \%$ \\
\hline Traumatic brain injury (TBI) & $\mathrm{H}$ & 168 & $10.65 \%$ \\
\hline Stroke & $\mathrm{H}$ & 865 & $54.85 \%$ \\
\hline Degenerative neurological pathologies & $\mathrm{H}$ & 272 & $17.25 \%$ \\
\hline Spinal cord injuries & $\mathrm{H}$ & 287 & $18.20 \%$ \\
\hline Nil per os (NP0) prescription & $\mathrm{H}$ & 126 & $7.99 \%$ \\
\hline Nasogastric tube (NGT) already in place & $\mathrm{H}$ & 354 & $22.45 \%$ \\
\hline $\begin{array}{l}\text { Percutaneous endoscopic gastrostomy } \\
\text { (PEG) already in place }\end{array}$ & $\mathrm{H}$ & 76 & $4.82 \%$ \\
\hline Indirect therapy & $\mathrm{H}$ & 1024 & $64.93 \%$ \\
\hline Direct therapy & $\mathrm{H}$ & 1301 & $82.50 \%$ \\
\hline $\begin{array}{l}\text { Videofluoroscopic swallowing study } \\
\text { (VFSS) already performed }\end{array}$ & $\mathrm{H}$ & 46 & $2.92 \%$ \\
\hline Tracheotomy & B & 286 & $18.14 \%$ \\
\hline Dysarthria & B & 341 & $21.62 \%$ \\
\hline Aphasia & B & 147 & $9.32 \%$ \\
\hline Cooperation & B & 1164 & $73.81 \%$ \\
\hline Gurgling voice & B & 150 & $9.51 \%$ \\
\hline Laryngeal elevation & B & 988 & $62.65 \%$ \\
\hline Sensation & B & 1444 & $91.57 \%$ \\
\hline Aspiration & $E$ & 382 & $24.22 \%$ \\
\hline Spillage & E & 687 & $43.56 \%$ \\
\hline Pre swallowing penetration & E & 581 & $36.84 \%$ \\
\hline Pooling & $\mathrm{E}$ & 1110 & $70.39 \%$ \\
\hline Pooling max amount & E & 156 & $9.89 \%$ \\
\hline Post swallowing penetration & E & 110 & $6.98 \%$ \\
\hline Delayed triggering & E & 524 & $33.23 \%$ \\
\hline Dry swallowing & E & 1045 & $66.27 \%$ \\
\hline
\end{tabular}

py, i.e. exercises performed to strengthen the oral phase of swallowing, and direct therapy, i.e. use of food and liquids to practice swallowing techniques, manoeuvres, indirect exercises) ${ }^{14}$ and MBS tests, even if performed elsewhere. With respect to BSE ${ }^{4514}$, clinical signs closely related to dysphagia and aspiration were considered. For example, gurgling was evaluated as a perceptive parameter of the voice, laryngeal elevation considering the movements of the larynx during a volitional swallow (a movement equal or superior to $2 \mathrm{~cm}$ was considered normal), sensation slightly touching with a probe the mouth and pharynx (the answer and/or reaction of the patients were considered), and finally cooperation. Cooperation refers, in the broadest sense, to consciousness, alertness, fatigability and cognitive abilities: it is a parameter affecting clinical evaluation, treatment and the possibility of oral feed- 
ing ${ }^{15}{ }^{16}$. All patients were evaluated by a phoniatrician and submitted to endoscopic evaluation according to the protocol in use in our centre ${ }^{617}$. Endoscopic evaluation was performed with a Storz endoscope (model 11101RP2, $30 \mathrm{~cm}$ long, $3.5 \mathrm{~mm}$ in diameter) and recorded on a workstation (Xion medical products $\mathrm{GmbH}$, Berlin Buchholz). The patients were given three trials of different consistencies: $5 \mathrm{cc}$ puree, $5 \mathrm{cc}$ liquid dye with $5 \%$ methylene blue and $1 / 4$ cracker (regular consistency) ${ }^{18}$. Patients were instructed to prepare the bolus and then to swallow without any command. Some patients were not able to test all the three consistencies, owing to the severity of their complaint. After each trial, dry swallows, performed to clear the bolus residue, were counted to apply the pooling score (p-score) (Table II). After FEES, several parameters were considered: spillage, delayed trigger (more than $0.5 \mathrm{sec}$ after bolus' pharyngeal entrance), penetration (before and after swallowing), aspiration and residue. Aspiration during FEES (however it occurred) was considered as the cut-off in dividing the population into two groups, nonaspirating and aspirating, if at least one bolus had passed below the vocal cords. As in previous studies ${ }^{12}{ }^{19}$, material pooling was endoscopically related to site, amount and management, and clinically related to sensation, collaboration and age. Management of pooling was related to the number of dry swallows or any other spontaneous or requested activity attempted by the patient to clear pooling: gurgling, clearing and coughing. Two scores were derived, viz. the pooling score (p-score) and the poolingsensation, collaboration, age score ( $\mathrm{p}$-SCA score) capable of expressing the severity of dysphagia (Table II).

With respect to data available for all the patients, 27 variables were considered (Table I). All the variables were dichotomous, taking on a value of 0 or 1 , signifying the absence or presence, respectively, of the characteristic (aspiration). Age dichotomy had a value of 1 if the patient was over 65 years old. The variable "maximum amount" was 1 if the amount of pooling was maximum and 0 if minimum or coating, in accordance with the p-score and p-SCA score.

As just stated, this study was based on a retrospective analysis and much data were either unavailable or irretrievable during collection: the dichotomous collection of data allowed us to fill this gap. Such an approach, although apparently simplistic, was nevertheless appropriate to the nature of certain parameters (i.e. sex, presence of certain pathological conditions, presence of tracheotomy or alternative feeding devices, or some FEES parameters) and, in general, suitable for the purposes of the study.

The pooled data were subsequently submitted to logistic regression to better understand the impact of individual factors (risk factors) with aspiration. The model was assessed using the maximum likelihood method.

Patients with missing data were omitted in bivariate and multivariate analysis, so that the actual number of patients evaluated was 1386 .

The study was approved by the institutional Research Review Board.

Statistical analysis was performed with Intercooled STATA 8.0 for Windows software.

\section{Results}

The parameters selected (independent variables) are reported in Table I. The bivariate relationship between each of the 27 risk factors and aspiration was studied. Associa-

Table II. Pooling score (p-score) and Pooling sensation-collaboration-age score (p-SCA score).

\begin{tabular}{|c|c|c|c|c|c|}
\hline \multirow[t]{2}{*}{ Pooling } & \multirow{2}{*}{\multicolumn{2}{|c|}{ Endoscopic landmarks }} & \multicolumn{3}{|c|}{ Bedside parameters } \\
\hline & & & Sensation & Cooperation & Age (yrs) \\
\hline Site & $\begin{array}{l}\text { Vallecule/marginal zone } \\
\text { Pyriform sinus } \\
\text { Vestibule/vocal cords } \\
\text { Lower vocal cords }\end{array}$ & $\begin{array}{l}1 \\
2 \\
3 \\
4\end{array}$ & \multirow{4}{*}{$\begin{array}{l}\text { Presence }=-1 \\
\text { Absence }=+1\end{array}$} & \multirow{3}{*}{$\begin{array}{l}\text { Presence }=-1 \\
\text { Absence }=+1\end{array}$} & \multirow{4}{*}{$\begin{array}{l}+1(<65) \\
+2(65-75) \\
+3(>75)\end{array}$} \\
\hline Amount & $\begin{array}{l}\text { Coating } \\
\text { Minimum } \\
\text { Maximum }\end{array}$ & $\begin{array}{l}1 \\
2 \\
3\end{array}$ & & & \\
\hline Management & $\begin{aligned} & <2 \\
2 & ><5 \\
& >5\end{aligned}$ & $\begin{array}{l}2 \\
3 \\
4\end{array}$ & & & \\
\hline Score & p 4-11 & & & p-SCA 3-16 & \\
\hline
\end{tabular}

p-score: 4-5: minimum score, corresponding to no endoscopic signs of dysphagia; 6-7: low score, corresponding to a mild dysphagia; 8-9: middle score, corresponding to a moderate dysphagia; 10-11: high score, corresponding to a severe dysphagia.

p-SCA score: 3-4: minimum score, corresponding to no dysphagia; 5-8: low score, corresponding to a mild dysphagia; 9-12: middle score, corresponding to a moderate dysphagia; 13-16: high score, corresponding to severe dysphagia. 
tion of categorical variables with aspiration was assessed with the $\chi^{2 \text {-test. }}$

The categorical variables found to be significantly associated ( $p$ value of less than 0.05 ) with aspiration were: age over 65, cooperation, gurgling voice, sensation, laryngeal elevation, nil per os (NPO) prescription, nasogastric tube (NGT) already in situ, indirect therapy, direct therapy, tracheotomy, delayed triggering, spillage, penetration, material pooling, post-swallowing penetration, dry swallowing and pooling maximum amount.

The average age of patients in the sample was 66.22: the cut-off age of 65 could indeed represent a risk factor for the appearance of deglutition disorders even as a co-morbidity factor.

Other parameters were not significantly associated with aspiration. Table III summarises the parameters correlated with aspiration and the respective odds ratios.

Although all these variables were eligible for entry into a multiple logistic regression model, some were excluded because they were strongly associated with other variables, thereby avoiding collinearity (delayed triggering, penetration and maximum amount). The association among variables was assessed with a $\chi 2$-test $(\mathrm{p}<0.05)$. Other variables were eliminated when statistically insignificant on the basis of likelihood ratio tests $(p>0.05)$. Multiple logistic regression modelling generated a maineffect model containing 8 variables, as reported in Table IV.
Table IV presents (using the maximum likelihood method) the adjusted odds ratios, estimated standard errors (SEs) and $95 \%$ confidence intervals (CIs) for the adjusted ratios for the model. It can be seen that the variables closely related with aspiration were age over 65 , cooperation, NPO prescription, tracheotomy, spillage, material pooling, post-swallowing penetration and dry swallowing. For example, an odds ratio of 19.24 for pooling means that a patient having this condition (without dry swallowing) would be 19.24 times more likely to aspirate than another patient not having that condition, controlling simultaneously for all other variables in the model. Patients able to perform dry swallows were $77 \%$ less likely to aspirate (protective factor).

It is worth pointing out that the retrospective nature of the study and the a priori consideration of aspiration means that the statistical models developed to correlate the data of our sample have no real predictive value. Thus, the odds ratios produced by multivariate analysis indicate the relationship between each variable and endoscopic results, taking into account the other variables in the model.

\section{Discussion}

We evaluated data from BSE and FEES in 1386 of 1577 patients with swallowing disorders due to different aetiologies and comorbidities. Of these, 382 (24.24\%) were aspirating, without any further information regarding the

Table III. Bivariate analyses: variables associated with aspiration and respective odds ratios.

\begin{tabular}{|c|c|c|c|c|}
\hline Risk Factor & $\begin{array}{l}\text { No. aspirating with risk } \\
\text { factor }(\%)\end{array}$ & $\begin{array}{l}\text { No. aspirating without } \\
\text { risk factor }(\%)\end{array}$ & Odds ratio & $95 \% \mathrm{Cl}$ \\
\hline Age over 65 years & $130(14.3)$ & $115(12.7)$ & 1.4 & $1.1-2.1$ \\
\hline Cooperation & $160(17.6)$ & $87(9.6)$ & 0.3 & $0.3-0.5$ \\
\hline Gurgling voice & $34(3.7)$ & 211 (23.2) & 2.6 & $1.5-43$ \\
\hline Sensation & 225 (24.8) & $21(2.3)$ & 0.4 & $0.2-0.8$ \\
\hline Laryngeal elevation & $89(9.8)$ & $157(17.3)$ & 0.11 & $0.1-0.19$ \\
\hline NPO prescription & $38(4.2)$ & $207(22.8)$ & 3.9 & $2.8-7.9$ \\
\hline NGT already placed & $106(11.7)$ & $141(15.5)$ & 6.7 & $4.4-9.2$ \\
\hline Indirect therapy & $224(24.6)$ & $23(2.5)$ & 8.5 & $5.7-15$ \\
\hline Direct therapy & $191(21)$ & $56(6.2)$ & 0.3 & $0.2-0.5$ \\
\hline Tracheotomy & 95 (10.5) & $152(16.7)$ & 9 & $5.9-13.8$ \\
\hline Delayed triggering & $130(14.3)$ & $115(12.7)$ & 3.3 & $2.1-4$ \\
\hline Spillage & 181 (19.9) & $65(7.2)$ & 4.6 & $3.2-6.2$ \\
\hline Pre swallowing penetration & $204(22.5)$ & $41(4.5)$ & 16.5 & $10.7-23.8$ \\
\hline Pooling & $232(25.6)$ & $13(1.4)$ & 8.6 & $4-14.1$ \\
\hline Pooling max amount & $61(8.9)$ & $163(23.8)$ & 4.5 & $2.5-6.5$ \\
\hline Post swallowing penetration & $50(5.5)$ & $195(21.5)$ & 6.7 & $4.3-133$ \\
\hline Dry swallowing & $201(22.1)$ & $44(4.9)$ & 2.3 & $1.4-3$ \\
\hline
\end{tabular}


Table IV. Multivariate analyses: variables associated with aspiration and respective odds ratios.

\begin{tabular}{|c|c|c|c|c|c|}
\hline Risk factor & Odds ratio & Std. Err & $z$ & $p>z$ & $95 \% \mathrm{Cl}$ \\
\hline Age over 65 years & 1.57 & 0.2466294 & 2.90 & 0.004 & $1.1-2.1$ \\
\hline Cooperation & 0.48 & 0.0870088 & -4.02 & 0.000 & $0.3-0.6$ \\
\hline NPO prescription & 2.34 & 0.6875621 & 2.90 & 0.004 & $1.31-4.16$ \\
\hline Tracheotomy & 11.95 & 2.317162 & 12.80 & 0.000 & $8.17-17,48$ \\
\hline Spillage & 4.7 & 0.8057423 & 9.04 & 0.000 & $3.4-6.6$ \\
\hline Pooling & 19.24 & 7.121247 & 7.99 & 0.000 & $9.3-39.7$ \\
\hline Post swallowing penetration & 4.39 & 1.083994 & 6.00 & 0.000 & $2.7-7.12$ \\
\hline Dry swallowing & 0.23 & 0.0672686 & -5.05 & 0.000 & $0.13-0.41$ \\
\hline
\end{tabular}

timing of aspiration, 581 (36.84\%) had penetration before swallowing and $110(6.98 \%)$ after swallowing. This means that overall $1073(77.41 \%)$ patients in our sample had airway invasion. This is probably due to the characteristics of the patients afferent to our centre, selected for their severity. Nevertheless, no aetiological correlation initially considered was, per se, statistically related to aspiration (Table I), but rather factors associated with other conditions (tracheostomy, parenteral nutrition, NGT or PEG) that best express the frailty of patients (Table III). Age was found to be statistically significant ${ }^{112}$. The average age of our sample was 66.22 years: the cut-off age of 65 could indeed represent a risk factor for the appearance of deglutition disorders even as a comorbidity factor. Moreover, cooperation was found to be correlated with aspiration, but with a negative odds ratio $(0.3)$, that is cooperating patients are less prone to aspirate than noncooperative patients.

In bivariate analysis, patients who underwent oro-motor therapy (indirect therapy) maintained a greater risk of aspiration, while the use of manoeuvres and postures (direct therapy) apparently served as protective factors. Although in the literature the clinical utility of oro-motor exercises is an open issue ${ }^{1420}$, this fact, per se, should be evaluated with circumspection. In our sample, many patients were hospitalised in other facilities, and no information about exercise programs for any single patient was available.

Another notable initial finding was the association of all the selected endoscopic parameters with aspiration, including management of material pooling, with dry swallowing or other reflex activities (endoscopically verified): all these parameters had a positive OR (Table III). The amount of material pooling (secretions or residue) and its management is a parameter able to express severity of dysphagia, as expressed by the p-score (Table II). The correlation between spontaneous swallowing activity and respiratory complications in elderly dysphagic patients was underlined decades ago ${ }^{21}$, though more recently in stroke patients ${ }^{22}$. In our sample, multivariate analysis (Table IV) showed that dry swallowing becomes a protective factor in patients with residue, who are able to reduce aspiration. With this assumption, the number of dry swallows or other activities attempted by patients to clear secretions or residue can be assumed to be a parameter expressing the efficiency of the swallowing act, related with the effectiveness of the same swallowing act, and protecting the airway from invasion. However, this data does not seem to be in accordance with recent research in the literature ${ }^{23}$ documenting an increase of aspiration risk on the subsequent swallow for thin-liquid single bolus in neurological patients.

Nevertheless, most of the instrumental findings can have an equivalent in bedside signs, i.e., wet voice, cough before, during or after bolus passage through the pharynx. FEES, in spite of its limitations, can better define the anatomical-functional events already highlighted through BSE (i.e. determining the amount and site of material pooling in a patient with gurgling voice, the pre/post swallowing nature of cough during the bolus tests, if only and when penetration occurred), optimally evaluate material pooling or residue and its management (clinical severity) and provide the therapist with precise information in order to plan treatment.

With both bedside and instrumental assessment, the clinician collects the best information to balance overestimating and underestimating clinical trends, clarify physiopathology and plan treatment. With the contribution of instrumental evaluation, the risk of lost episodes of silent aspiration/penetration at the bedside is less, but the risk of generalised pathological random or extraordinary airway invasion events is higher ${ }^{1011}$.

\section{Conclusions}

In daily clinical practice, the possibility of correlating signs and symptoms with aspiration in patients with deglutition disorders is an important goal to prevent com- 
plications. Considering the large sample of patients from which dysphagia parameters were derived, taken from bedside evaluation and FEES, able to support a possible aspiration event, aspiration alone does not define dysphagia and its severity (underestimation/overestimation risk). The data from our sample offer us a range of parameters to better classify patients with a swallowing disorder.

Apart from the aim of our study, bivariate and multivariate analyses underline the parameters that are potentially useful in planning a scale of severity accompanied by therapeutic options.

The main limit of our dataset is that it is not comprehensive of all BSE and FEES parameters, due to the collection of data over a long period and the lack of information that was not retrievable at the moment of assessment of patients.

\section{Conflict of interest statement}

None declared.

\section{References}

1 Serra-Prat M, Hinojosa G, López D, et al. Prevalence of oropharyngeal dysphagia and impaired safety and efficacy of swallow in independently living older persons. J Am Geriatr Soc 2011;59:186-7.

2 Vergis EN, Brennen C, Wagener M, et al. Pneumonia in longterm care: A prospective case-control study of risk factors and impact on survival. Arch Intern Med 2001;161:2378-81.

3 Roden DF, Altman KW. Causes of dysphagia among different age groups: A systematic review of the literature. Otolaryngol Clin North Am 2013;46:965-87.

4 McCullough GH, Rosenbek JC, Wertz RT, et al. Utility of clinical/swallowing examination measures for detecting aspiration post-stroke. J Speech Lang Hear Res 2005;48:1280-93.

5 Speyer R. Oropharyngeal dysphagia screening and assessment. Otolaryngol Clin North Am 2013;46:989-1008.

6 Langmore SE, Schatz K, Olsen N. Fiberoptic endoscopic examination of swallowing safety: a new procedure. Dysphagia 1988;2:216-9.

7 Logemann JA. Evaluation and treatment of swallowing disorders. Austin Texas: Pro Ed 1998.

8 McHorney CA, Robbins J, Lomax K, et al. The SWAL-QOL and SWAL-CARE outcomes tool for oropharyngeal dysphagia in adults: III. Documentation of reliability and validity. Dysphagia 2002;17:97-114.
9 Ekberg O, Hamdy S, Woisard V, et al. Social and psychological burden of dysphagia: its impact on diagnosis and treatment. Dysphagia 2002;17:139-46.

10 Leder BS, Espinosa JF. Aspiration risk after acute stroke: comparison of clinical examination and fiberoptic endoscopic evaluation of swallowing. Dysphagia 2002;17:214-8.

11 Farneti D, Genovese E. Endoscopic criteria in assessing severity of swallowing disorders. In: Speyer R, editor. Seminars in dysphagia. London: InTech; 2015. pp. 71-90.

12 Farneti D. Pooling score: an endoscopic model for evaluating severity of dysphagia. Acta Otorhinolaryngol Ital 2008;28:135-40.

13 O'Neil KH, Purdy M, Falk J, et al. The dysphagia outcome and severity scale. Dysphagia 1999;14:139-45.

14 Murry T, Carrau RL. Clinical manual of swallowing disorders. San Diego: Singular Thomson Learning; 2001.

15 Logeman JA, Veis S, Colangelo L. A screening procedure for oropharyngeal dysphagia. Dysphagia 1999;14:44-51.

16 Parker C, Power M, Hamdy S, et al. Awareness of dysphagia by patients following stroke predicts swallowing performance. Dysphagia 2004;19:28-35.

17 Farneti D. Valutazione video endoscopica. In: Schindler O, Ruoppolo G, Schindler A, editors. Deglutologia. Torino: Omega Editore; 2001. p. 167.

18 Cichero JA, Steele C, Duivestein J, et al. The need for international terminology and definitions for texture-modified foods and thickened liquids used in dysphagia management: foundations of a global initiative. Curr Phys Med Rehabil Rep 2013;1:280-91.

19 Farneti D, Fattori B, Nacci A, et al. The Pooling-score ( $P$ score): inter-and intra-rater reliability in endoscopic assessment of the severity of dysphagia. Acta Otorhinolaryngol Ital 2014;34:105-10.

20 Langmore SE, Pisegna JM. Efficacy of exercises to rehabilitate dysphagia: a critique of the literature. Int J Speech Lang Pathol 2015;17:222-9.

21 Murray J, Langmore SE, Ginsberg S, et al. The significance of accumulated oropharyngeal secretions and swallowing frequency in predicting aspiration. Dysphagia 1996;11:99-103.

22 Crary MA, Carnaby GD, Sia I, et al. Spontaneous swallowing frequency has potential to identify dysphagia in acute stroke. Stroke 2013;44:3452-7.

23 Molfenter SM, Steele CM. The relationship between residue and aspiration on the subsequent swallow: an application of the normalized residue ratio scale. Dysphagia 2013;28:494-500. 